\title{
Features of transient hypogammaglobulinaemia in infants screened for immunological abnormalities
}

\author{
A M Walker, A S Kemp, D J Hill, M J Shelton
}

\begin{abstract}
The incidence of transient hypogammaglobulinaemia of infancy (THI) detected in a major paediatric centre over a 10 year period was examined. A total of 2468 subjects less than 2 years of age had an IgG measurement taken between July 1979 and March 1990. Subjects with known immunodeficiencies were excluded. Fifteen patients were classified as having THI with an initial IgG level less than the fifth centile followed by a second measurement within the normal range. A further 24 patients were identified as having possible THI with a single low IgG concentration. There were 60174 live births each year in Victoria in the years 1979-88. This gives an incidence of proved THI of 23 per $10^{6}$ births, and including proved and probable THI an incidence of 61 per $10^{6}$ live births.

Of those patients with proved THI 12/15 had symptoms of either atopic disease or food allergy/intolerance and three had gastrointestinal symptoms without any evidence of atopic disease. At presentation $12 / 15(80 \%)$ were IgA deficient and 9/15 had IgM concentrations less than the 20 th centile for age. It is suggested that in view of the preponderance of atopic and food intolerant patients that subclinical protein loss from the bowel due to allergic inflammation may be a contributing factor to the development of THI in some patients.
\end{abstract}

(Arch Dis Child 1994; 70: 183-186)

Transient hypogammaglobulinaemia of infancy (THI) was first described in $1956 .{ }^{1}$ It is considered to be characterised by an abnormal delay in the onset of immunoglobulin synthesis with accentuation and prolongation of the physiological hypogammaglobulinaemia seen in infants. ${ }^{2}$ The incidence of this disorder is uncertain. Tiller and Buckley ${ }^{3}$ found 11 cases in over 10000 serum samples examined and suggested 'This is not a common entity'. ${ }^{3}$ Dressler $e t a l$, who identified five cases in more than 8000 serum samples, also considered it to be uncommon. ${ }^{4}$ McGready, however, described 23 patients referred from only five paediatricians over eight years and considered that THI is 'not infrequently discovered in clinical practice if sought'. ${ }^{2}$ The clinical features are varied with some subjects having recurrent infections while others are asymptomatic. In most series atopic disease has not been a prominent feature, ${ }^{2-4}$ though Fineman et al described four infants with THI, increased IgE concentrations, and food allergy. ${ }^{5}$
The clinical immunology department of the Royal Children's Hospital is the only paediatric clinical immunology centre for the state of Victoria, which has a population of about four million people. Previous data from this department have been used to document the occurrence of immunodeficiency diseases within Victoria. ${ }^{67}$ In this paper we describe the incidence and clinical features of THI as detected in our clinical immunology laboratory over a 10 year period.

\section{Study population}

Eligible patients were all those children less than 2 years of age who had an IgG estimation which was below the fifth centile of the laboratory mean for age ${ }^{8}$ during the study period from July 1979 to March 1990. The fifth centile for IgG concentrations is $2.90(0.1$ years), $1.45(0.2-0.6$ years $), 2.02(0.6-0.8$ years), $2 \cdot 10(0 \cdot 8-1 \cdot 0$ years), and $2 \cdot 82 \mathrm{~g} / \mathrm{l}$ (1-2 years). During this period 2468 children of this age group had 3243 immunoglobulin estimations. Clinical data were collected from hospital unit records and the records of private paediatricians. Children with a known congenital immunodeficiency disorder were excluded from further analysis.

\section{Results}

Sixty six infants were identified with hypogammaglobulinaemia. Twenty four of these were excluded because of an identifiable cause (protein losing enteropathy, 12; nephrotic syndrome, six; prematurity (less than 35 weeks' gestational age), five; or maternal hypogammaglobulinaemia, one). Eighteen patients (11 boys, seven girls) were identified as having 'proved THI' with an initial IgG concentration less than the fifth centile followed by a second measurement within the normal range. A further 28 children were identified as 'probable THI' having a single low IgG measurement without any subsequent diagnosis of immunodeficiency being made.

In the group of proved THI three children were noted to have a low IgG concentration in association with a severe illness: one with staphylococcal empyema, one with varicella, and one with sepsis after resection of bronchogenic cyst. The child with severe varicella had a normal level of IgG (19th centile) at the time of presentation at 8 months of age, and three days later IgG was less than the fifth centile. The immunoglobulin levels returned to normal within six weeks in all three patients: These three patients were excluded from the subsequent categorisation of THI. Four children 
Table 1 Clinical features of transient hypogammaglobulinaemia of infancy (THI). Values are number of children

\begin{tabular}{lcccccc}
\hline & \multicolumn{2}{c}{ Proved THI } & & & \multicolumn{2}{c}{ Probable THI } \\
\cline { 2 - 3 } & Boys & & Girls & & Boys & Girls \\
\hline Atopy, food allergy, or intolerance & 8 & 4 & & 9 & 2 \\
Gastrointestinal symptoms & 2 & 1 & & 1 & 0 \\
Failure to thrive & 0 & 0 & & 1 & 0 \\
Unclassified symptoms & 0 & 0 & & 8 & 3 \\
Total & 10 & 5 & & 19 & 5 \\
\hline
\end{tabular}

with hypogammaglobulinaemia associated with severe life threatening illnesses were identified in the probable THI group and were not included in further analysis.

The remaining patients were classified according to clinical presentation (table 1). Twelve patients with proved THI had symptoms of either atopic disease or food allergy/ intolerance and three had gastrointestinal symptoms without evidence of atopic disease. Patients with probable THI often presented with atopy or food allergy/intolerance (11 patients), gastrointestinal symptoms (one patient), or failure to thrive (one patient). Clinical information was inadequate in 11 patients in this group. The male to female ratio was 2.9:1 when the two groups were considered together. The mean age at presentation was 10 months (range 2-24 months); the mean age at the resolution of normal IgG concentrations in those with proved THI was 22 months (range 9-43 months).

Hypogammaglobulinaemia often affected more than one class of immunoglobulin; table 2 gives the corresponding centiles for $\operatorname{IgM}$ and IgA at the time of presentation and resolution in the proved THI group. Twelve $(80 \%)$ of the 15 patients had IgA concentrations less than the fifth centile for age and nine $(60 \%)$ of the 15 had IgM concentrations less than the 20 th centile for age.

The principal symptoms of the 12 patients with THI in the atopy food allergy group were cows' milk protein intolerance (four patients), asthma (three patients), asthma and eczema (two patients), and asthma and immediate food hypersensitivity reactions (one patient). Two of the patients with a low serum albumin level are described in more detail. One patient aged 6 months had atopic dermatitis and a diagnosis of allergic enteropathy due to cows' milk protein intolerance. IgM was not detected

Table 2 IgA and IgM centiles in subjects with proved transient hypogammaglobulinaemia of infancy

\begin{tabular}{llll}
\hline $\begin{array}{l}\text { IgA at } \\
\text { diagnosis }\end{array}$ & $\begin{array}{l}\text { IgA at } \\
\text { resolution }\end{array}$ & $\begin{array}{l}\text { IgM at } \\
\text { diagnosis }\end{array}$ & $\begin{array}{l}\text { IgM at } \\
\text { resolution }\end{array}$ \\
\hline$<5$ & $<5$ & 17 & 31 \\
$<5$ & $<5$ & 15 & 15 \\
$<5$ & $<5$ & 7 & 49 \\
$<5$ & $<5$ & 29 & 94 \\
$<5$ & 9 & 5 & 14 \\
$<5$ & 10 & 6 & 22 \\
$<5$ & 10 & 7 & 75 \\
$<5$ & 12 & 58 & 85 \\
$<5$ & 15 & 31 & 43 \\
$<5$ & 18 & 15 & 23 \\
$<5$ & 40 & 64 & 13 \\
$<5$ & 78 & $<5$ & $<5$ \\
10 & 26 & 10 & 12 \\
12 & $<5$ & 90 & 7 \\
60 & 64 & 70 & 72 \\
\end{tabular}

at 6 months and her albumin was low at $18 \mathrm{~g} / 1$ (range 27-54). At 9 months her albumin was normal at $35 \mathrm{~g} / \mathrm{l}, \mathrm{IgG}$ was on the eighth centile, and IgM still less than the fifth centile. Faecal $\alpha_{1}$ antitrypsin clearance was normal at 6 months of age on two occasions despite the low serum albumin. At 22 months of age IgM had increased to the 15 th centile and $\operatorname{IgE}$ was increased $(207 \mathrm{IU} / \mathrm{ml}$; range $0-35 \mathrm{IU} / \mathrm{ml})$. The second child had marked erythroderma and a slight reduction of albumin at $26 \mathrm{~g} / \mathrm{l}$ (range 27-54) and an increased IgE of $127 \mathrm{IU} / \mathrm{ml}$ at the age of 3 months. At 9 months of age albumin was normal at $35 \mathrm{~g} / \mathrm{l}$ and $\mathrm{IgG}$ was just into the normal range (seventh centile), whereas IgE had increased markedly to 1080 $\mathrm{IU} / \mathrm{ml}$. Of the three children with THI and gastrointestinal symptoms without atopic disease, two had giardia on at least one occasion, and one child had lactose intolerance.

As a significant proportion of children with proved THI had symptoms of allergy and food protein intolerance diagnosed by the allergy unit, the question of sampling bias was raised. When the proportion of proved THI patients with allergy or food protein intolerance $(12 / 15)$ is compared with the proportion of immunoglobulin requests from the allergy unit over a period of 10 years (1410/3243) a significant difference is found between the proportion of children with THI from the allergy unit and the proportion of immunoglobulin requests ( $p=0.0046$; Fisher's exact test).

The clinical immunology laboratory is the only paediatric clinical immunology laboratory in Victoria and manages all the immunodeficient children in the state. There were 60174 live births per year in Victoria from 1979 to 1988 (Consultative Council on Paediatric Mortality and Morbidity. Annual report 1988). Considering only those cases of proved THI this indicates an incidence of 23 cases of THI per $10^{6}$ live births. The incidence of all THI (proved and probable) is 61 per $10^{6}$ live births. This may be compared with the incidence of other known immunodeficiencies previously calculated from the same laboratory (table 3). ${ }^{67}$

\section{Discussion}

The findings of this study allow an estimate of the incidence of THI. Diagnosed proved THI appears to be two to four times as common as other classical immunodeficiencies such as $\mathrm{X}$ linked hypogammaglobulinaemia or severe

Table 3 Incidence of immunodeficiency disorders in the state of Victoria, Australia. Total number of live births in Victoria 1979-88: 60174/year

\begin{tabular}{ll}
\hline Immunodeficiency disorder & $\begin{array}{l}\text { Incidence/10 } \\
\text { live births }\end{array}$ \\
\hline X linked hypogammaglobulinaemia with hyper & \\
IgM & $3^{\star}$ \\
X linked hypogammaglobulinaemia & $7^{\star}$ \\
Common variable hypogammaglobulinaemia & $12^{\star}$ \\
Symptomatic absolute IgA deficiency & $24^{\star}$ \\
Severe combined immunodeficiency & $14 \dagger$ \\
Proved THI & $23^{\star}$ \\
Proved and probable THI & 61
\end{tabular}

${ }^{\star}$ From data of Hosking and Roberton. ${ }^{6}$

†From data of Roberton and Hosking. ${ }^{7}$ 
combined immunodeficiency. It appears to be similar in incidence to symptomatic absolute IgA deficiency. ${ }^{6}$ The number of children with immunoglobulin levels less than the fifth centile (66) in our cohort of 2468 subjects is in fact less than the $5 \%$ of the cohort (123) which might be expected. There are several possible explanations for this. Firstly, children with a known and diagnosable congenital immune deficiency disorder were excluded from further analysis but were included in the number of immunoglobulin estimations performed. Secondly, as a large number of children were investigated for recurrent infections and those with a known immune deficiency disorder were excluded, the range of immunoglobulins may in fact be higher due to stimulation of the immune system. The original data from which the ranges were calculated excluded children with a history of recurrent infections. This is supported by a previous study from our laboratory which showed that of 656 children with recurrent infections, including those with a diagnosable immunodefiency disorder, only $3.6 \%$ had an IgG level below the fifth centile. ${ }^{9}$ Lastly, as there are considerably more subjects contributing to the study group than the normal range, it is possible that the fifth centile of the study group may differ slightly from that of the normal group.

At the time of the diagnosis, in addition to a low IgG level, there was a high incidence $(80 \%)$ of low serum IgA levels. A similar finding was noted by McGready. ${ }^{2}$ The low serum IgA concentration often resolved and only $20 \%$ of measurements were low at the time of recovery of IgG concentrations. It is notable that IgM concentrations were predominantly in the lower normal range with nine of 15 $(60 \%)$ being less than the 20 th centile at diagnosis. These observations suggest that the abnormality may be more generalised than one which affects IgG production alone. The duration of the THI was less than 24 months in all but one patient and is consistent with the findings in previous studies. ${ }^{23}$ More prolonged hypogammaglobulinaemia has been observed by other workers. ${ }^{2}$

Several causes of THI have been postulated. These include delayed maturation of $\mathbf{B}$ cell function, ${ }^{10}$ deficiencies of helper $\mathrm{T}$ cells, ${ }^{11}$ and a clinical heterozygous state of other more severe immunodeficiencies. ${ }^{12}$ It is also likely that some cases of THI may reflect normal children who fall below the lower end of a normal range, particularly as it has been shown that such children have a normal specific antibody response. ${ }^{3}$ The spectrum of clinical features and range of postulated aetiologies suggest that multiple factors may contribute.

A striking feature of this study was the preponderance of subjects with either atopy or food intolerance referred from the allergy unit. This has not been noted in previous studies, though Fineman et al described four infants with a combination of food allergy, transient hypogammaglobulinaemia, and increased serum IgE concentrations who were seen in an allergy clinic in a one year period. ${ }^{5}$ They considered that the transient hypogamma- globulinaemia was unlikely to be due to protein loss from the gut, though one of the four children in that study had a reduced serum albumin of $30 \mathrm{~g} / \mathrm{l}$. In a previous study of a large group of infants allergic to cows' milk we noted that the mean IgG concentrations were lower than controls, ${ }^{13}$ a finding consistent with the present results. Circulating IgG concentrations reflect a balance between production, catabolism, and protein loss. Subclinical IgG loss during infancy, particularly if production is also impaired, could explain the preponderance of atopic/food intolerant subjects seen in this study. Two children in this study had some suggestion of protein loss. One had a low albumin concentration at 6 months despite normal faecal $\alpha_{1}$ antitrypsin clearance on two occasions. In addition to a diagnosis of cows' milk protein enteropathy this child had a low IgM that persisted until 22 months of age despite the return of IgG and albumin to the normal range by 9 months of age. The low IgM concentration suggests that this child may have an abnormality of immunoglobulin production with protein loss further reducing the low IgG. The second child had a slightly low albumin $(26 \mathrm{~g} / \mathrm{l})$ at 3 months in association with a low IgG, with both being normal by 9 months of age. Two cases of hypoalbuminaemia in infants with atopic dermatitis have been described previously, ${ }^{14} 15$ though in these patients the IgG concentrations were normal. The protein loss was postulated to occur from the gut or skin. Jenkins et al speculated that protein loss from the bowel 'may perhaps be more common than previously realized'. ${ }^{14}$ Clearly if there is a tendency for reduced IgG production, an increased IgG loss through the bowel in atopic patients could predispose to hypogammaglobulinaemia. Thus a possible reason for the preponderance of atopic children and those with food intolerance in this study is that allergen induced gastrointestinal inflammation accentuates the loss of IgG. An alternative explanation is that the THI leads to the allergic or food intolerant state. Transient IgA deficiency in infancy is associated with atopy ${ }^{16}$; whether this is a causative relation or reflects an underlying common immune abnormality leading to the low IgA and increased IgE is uncertain. ${ }^{17}$ It is likely that no single abnormality is the cause of THI and different factors may be relevant in different patients.

In addition to the patients classified as THI we observed three subjects with a very brief period of hypogammaglobulinaemia associated with severe illness. IgG concentrations were noted to return to normal within six weeks in all patients. A previous paper describes one similar case under the title of $\mathrm{THI}^{18}$; however, we chose not to include these cases in the larger group of THI. Such rapid changes in IgG concentrations suggest that the hypogammaglobulinaemia is caused by increased loss or catabolism associated with the acute illness.

The immunology department of the Royal Children's Hospital has performed extensive investigations of children with recurrent infections for many years. ${ }^{19}$ It is of interest that 
recurrent infections do not feature in the clinical spectrum of children with THI, suggesting that THI does not generally predispose to a significant problem with infection. In our population the incidence of proved THI was the same as that of diagnosed absolute IgA deficiency (24 per $10^{6}$ live births). This is much less than the 1:500 to 1:700 incidence of selective IgA deficiency found in community surveys. ${ }^{19}$ By analogy with selective IgA deficiency, THI may not necessarily give rise to significant symptoms, thus it is likely that there is a significant group of children with undetected THI in the community.

1 Gitlin D, Janeway CA. Agammaglobulinemia: congenital acquired and transient forms. Prog Hematol 1956; 1 318-29.

2 McGready SJ. Transient hypogammaglobulinemia of infancy: need to reconsider name and definition. 7 Pediat 1987; 110: 47-50

3 Tiller TL, Buckley RH. Transient hypogammaglobulinemia of infancy: review of literature, clinical and immunologic features of 11 new cases, and long term follow up. $\mathcal{F}$ Pediatr 1978; 92: 347-53.

4 Dressler F, Peter HH, Muller W, Reiger CHL. Transient hypogammaglobulinaemia of infancy. Five new cases, review of literature, and definition. Acta Paediatr Scan 1989; 78: 767-74

5 Fineman SM, Rosen FS, Geha RS. Transient hypogamma globulinaemia, elevated immunoglobulin $\mathrm{E}$ levels, and food allergy. F Allergy Clin Immunol 1979; 64: 216-2.

6 Hosking CS, Roberton DM. Epidemiology and treatment of hypogammaglobulinaemia. Birth Defects 1983; 19: 223-7.
7 Roberton DM, Hosking CS. The long term treatment of childhood agammaglobulinemia in Melbourne with intravenous gammaglobulin 1972-1985. Dev Biol Standard 1986; 67: 273-80.

8 Shelton MJ, Meek F, Gollen I, Hosking CS. Serum immunoglobulin levels in children. Australian fournal of immunoglobulin levels in children.

9 Hosking CS, Fitzgerald MG, Shelton MJ. Results of immune function testing in children with recurrent immune function testing in children with

10 Rosen FS, Cooper MD, Wedgewood JP. The primary immunodeficiencies. $N$ Engl $\mathcal{F}$ Med 1984; 311: 300-10

11 Siegel RL, Issekutz T, Schwaber J, Rosen FS, Geha RS Deficiency of $\mathrm{T}$ helper cells in transient hypogammaglobulinemia of infancy. $N$ Engl 7 Med 1981; 305: 1307-13.

12 Soothill JF. Immunoglobulins in first degree relatives of patients with hypogammaglobulinemia. Lancet 1968; patients
$1001-3$

13 Hill DJ, Firer MA, Shelton MJ, Hosking CS Manifestations of milk allergy in infancy: clinical and immunologic findings. $\mathcal{F}$ Pediatr 1986; 109: $270-6$.

14 Jenkins HR, Walker-Smith JA, Atherton DJM. Proteinlosing enteropathy in atopic dermatitis. Pediatr Dermato 1986; 3: 125-9.

15 Abrahamov A, Schifmann R, Goldstein R, Tal Y, Freier S Growth failure due to protein loss in dermatitis. Eur $\mathscr{F}$ Pediatr 1986; 145: 223-6.

16 Taylor B, Normal AP, Orgel HA, Turner MW, Stokes CR, Soothill JF. Transient IgA deficiency and pathogenesis of intantile atopy. Lancet 1973; ii: 111-3.

17 Van Asperen PP, Gleeson M, Kemp AS, et al. The relationship between atopy and salivary IgA deficiency in infancy. Clin Exp Immunol 1988; 62: 753-7.

18 Kosnik EF, Johnson JP, Rennels MB, Caniano DA Streptococcal sepsis presenting as acute abdomen in a child with transient hypogammaglobulinemia of infancy. $\mathcal{J}$ Pedriatr Surg 1986; 21: 975-6.

19 Hong R, Amman AJ. Disorders of the IgA system. In Stiehm ER, ed. Immunologic disorders in infants and children. Philadelphia: Saunders, 1984: 329-42. 